\title{
Study of the efficiency of conveyors of mining transport systems of mining complexes
}

\author{
Maxsud. Kalandarovich Bobojanov ${ }^{1}$, Oripovich Eshmurodov Ziyodulla ${ }^{2}$, Muhriddin Tulkin \\ ugli Ismoilov $^{3}$,Eldor Izam ugli Arziev ${ }^{4}$, and Gulnoza Ziyodullaevna Togaeva ${ }^{5}$ \\ ${ }^{1}$ Tashkent state technical University, Tashkent, Uzbekistan \\ 2.3.4.5 Navoi state mining Institute, Navoi, Uzbekistan
}

\begin{abstract}
The current stage of development of open-pit mining is characterized by mining operations at great depths. Increasing the depth of quarries leads to an increase in the volume and distance of transportation of overburden and ore. Therefore, the task of building energy-efficient transport systems, improving the efficiency of existing belt conveyors of mining transport systems is one of the most urgent tasks. The article examines the efficiency of belt conveyors in mining transport systems mining complexes. Various electric drive systems that can be used on conveyors are compared. We have studied the relative inclination that affects the efficiency of conveyors, as well as parameters related to energy consumption, such as the speed of the belt or the width of the belt, as well as design methods. Various methods of controlling adjustable and non-adjustable electric drives and drag distribution effects drag distribution depending on the flow, the dependence of the belt tilt speed range on the flow, the dependence of power on the flow and the influence of gravity, the energy consumption of the conveyor system is calculated for different traction forces.
\end{abstract}

\section{Introduction}

Currently, the development of the opencast mining method is characterized by mining at great depths. It is known that increasing the depth of quarries leads to an increase in the volume and range of transportation of rocks and ores. This leads to economic problems of development of deposits, which at the present stage of development take on special importance. It is known from the literature sources that when the depth of the quarry increases by $100 \mathrm{~m}$, the expenses for transportation by dump trucks increase approximately in 1,5 times, and by $5 \ldots 6 \%$ by conveyors. [1].

\section{Results and discussion}

The task of building an energy-efficient transport system is reduced to justify the scheme of transportation of rock mass from the faces to the bunker, the calculation of freight flows, the choice of means of transport with the maximum possible efficiency, the 
definition of regime and operational parameters of transport means. The following empirical rule can be used for financial evaluation of energy saving measures (assumptions: continuous operation, electricity price for industrial consumers $0.12 \mathrm{um} / \mathrm{kWh}$ [2]):

\section{$\Delta \mathrm{K} / \Delta \mathrm{P}=0.12 \in / \mathrm{kWh} \cdot 24 \mathrm{~h} \cdot 365 \approx 1 \mathrm{sum} / \mathrm{W}$ per year}

A saving in power consumption of $1 \mathrm{~kW}$ approximates a saving of $1000 \in$ per year.

Materials and methods research of various factors influencing efficiency

Increased performance under load is often cited as the main reason for increased power consumption by the drive system. Load increases are often considered the primary cause of increased power consumption in a drive system. Estimates of potential cost savings are made with known ratios for power consumption:

$$
\text { Ppump } \sim \mathrm{Q} \cdot \mathrm{H} \text {; or Pconveyor } \sim \mathrm{F} \cdot \mathrm{V} \text {. }
$$

If the load increase of $20 \%$ were to increase both the load flow and the potential size of the load volume, this would lead to the creation of pumping and conveyor systems in accordance with ( 1 At the same time, electricity consumption would increase by $44 \%$. This approach leads to the wrong result. An increase in productivity only changes the design and/or mode of operation of the system., the choice of system components, but not the actual load on the system.

However, an increase in productivity has a significant impact on energy consumption. The impact of oversize components through a $20 \%$ overload for ensuring productivity has been investigated using the results of calculations from design programs for the pump and conveyor drive systems.

The studies are based on belt conveyor calculations. Different drive systems are compared. Since the formulas have usually been determined empirically, the calculated absolute drag and consumption is an approximate solution. The relative slopes and energy consumption dependencies of parameters such as belt speed or belt width as well as the resulting design procedure are generally acceptable [3].

Technical characteristics of the investigated conveyor drive system. The parameters for the simulation are given in Table 1.

Table 1. Technical characteristics of parameters of the investigated conveyor drive system

\begin{tabular}{|c|c|}
\hline parameter & value \\
\hline Bulk density (mountain mass) & $\rho=1750 \mathrm{~kg} / \mathrm{m} 3$ \\
\hline static tilt angle (rock mass) & $\beta=370$ \\
\hline dynamic tilt angle (rock mass) & $\beta \mathrm{din}=200$ \\
\hline thick coat of cover & $3 \mathrm{~mm}$ \\
\hline Drum drive friction coefficient & $\mu \mathrm{tr}=0.35$ \\
\hline Stretch roll diameter & $\mathrm{dR}=22 \mathrm{~cm}$ \\
\hline Inner diameter of the rolling bearing & $\lambda=5 \mathrm{~cm}$ \\
\hline Angle of the trough & $10=1 ; 36^{\circ}$ \\
\hline Distance between upper blank stations & $10=2.510$ \\
\hline Distance between lower idle stations & $\mathrm{v} 0=0.5 \mathrm{~m} / \mathrm{s}$ \\
\hline Feed speed & $\mathrm{d}$ \\
\hline
\end{tabular}

Depending on the type of the system under investigation, individual parameters of the conveyor system vary. Additional technical characteristics: 
* conveyor line $\mathrm{lF}$ of the plant is $270 \mathrm{~m}$

* the height of the $\mathrm{H}$ system is $2 \mathrm{~m}$

* maximum jmax output is $3500 \mathrm{t} / \mathrm{h}$

* the conveyor belt is a steel belt, has a width of $2 \mathrm{~m}$ and is filled to the maximum $\varphi$ fill $=1$

Drives are accepted by default:

* Motor type: IE2 asynchronous motors

- Motor control (speed-controlled): Control - U/f.

* Drive option 1 (one head drive without tail drive drum)

We study the influence of different methods of control and distribution of resistances.

Calculated resistances are obtained depending on the selection of unregulated and adjustable actuators, as shown in Figures $1 \mathrm{a}$ and $1 \mathrm{~b}$. In the case of non-adjustable actuators, the filling degree is proportional to the capacity and the tape speed of the tape, remains constant (Fig. 2). In the case of variable speed electric drives with variable speed, the change of the belt speed (see Fig. 2), the filling ratio was kept constant even when the speed was reduced [4].

\begin{tabular}{|l|l|l|l|l|}
\hline St \\
$\square$
\end{tabular}$F_{\mathrm{SF}} \square F_{\mathrm{E}} \square F_{\mathrm{R}} \square F_{\mathrm{n}}$

FSt ... Tilt resistance FSF ... resonant bending resistance FE ... rolling pressure resistance FR ... Rolling resistance

Fn ... added resistance

\section{Networking}

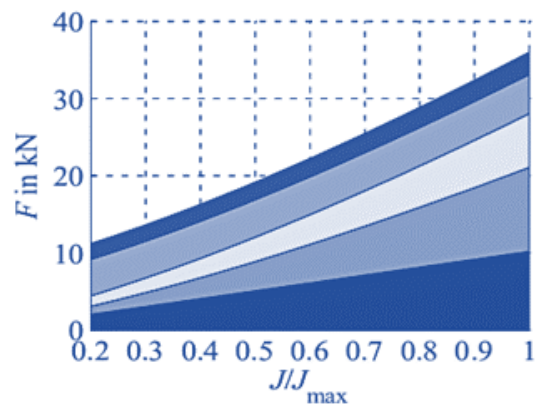

(a) conveyor system with mains motor
Speed regulation

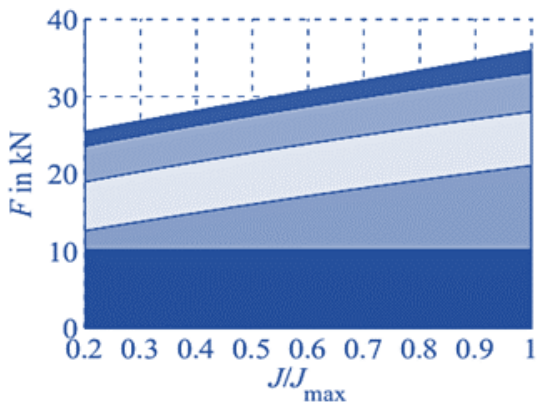

(b) a conveyor with adjustable motors speeds

Fig. 1: Calculated resistance distribution $\mathrm{F}$ depending on the performance $\mathrm{J}$ 


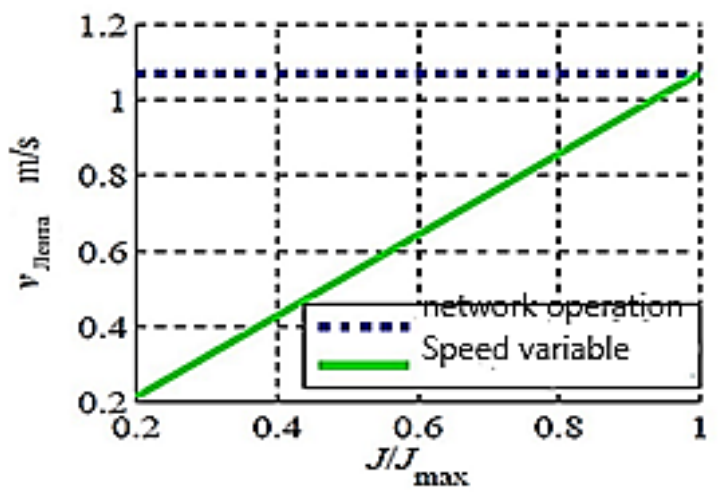

Fig. 2. Calculated slope of the belt speed range of the tape, depending on the capacity $J$

Based on the power distribution, the power distribution for the unregulated and variable speed drive is calculated as shown in Figures $3 \mathrm{a}$ and $3 \mathrm{~b}$.

In figure $3 \mathrm{a}$ and $3 \mathrm{~b} .3 \mathrm{a}$ shows the resulting power consumption for the unregulated and the variable speed actuator in Fig. 1a and 1b. When the power consumption of the power supply strictly connected to the mains decreases, in the case of the variable speed drive (speed control) there are additional losses of the transducer and harmonic losses in the motor. Thus, the further the unit is operated in the partial load range, the more efficient its use with the variable speed drive will be.

$\square P_{\mathrm{St}} \square P_{\mathrm{H}} \square P_{\mathrm{n}} \square P_{\mathrm{V} \text { Get }} \square P_{\mathrm{V} \text { Mot }} \square P_{\mathrm{V} \mathrm{Umr}}$

PSt...Tilt Power PH...Main Resistance Power Pn...Secondary Resistance Power
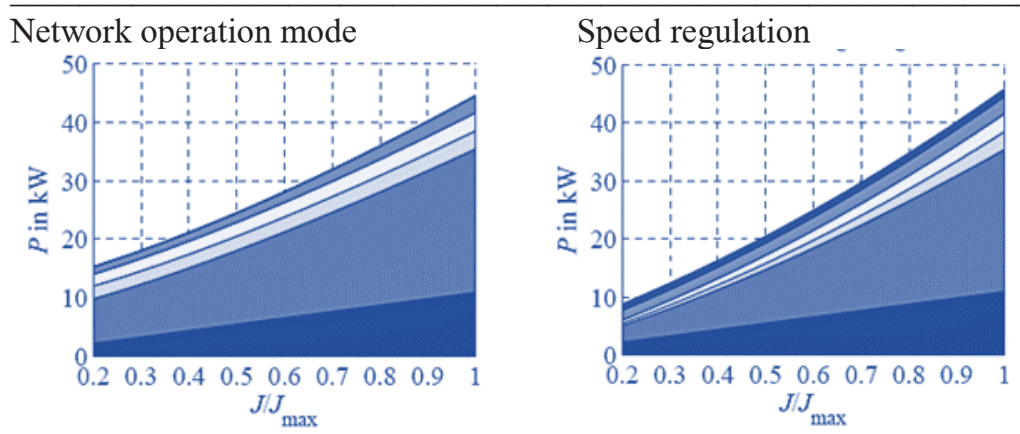

Fig. 3. Calculated power distribution $\mathrm{P}$ as a function of capacity $\mathrm{J}$

Drive efficiency $п п р$ is based on the product of a gearbox, motor and inverter and always smaller with control speed than with the network mode, as shown in the figure. $4 \mathrm{~b}$. Nevertheless, the required capacity of the conveyor belt drive when using a frequencycontrolled electric drive by the equation of

$$
P_{\text {mex }}=F_{\text {nor }}(J, H) \cdot v(J, H)
$$


in the range of partial loads less. This reduces the partial load range despite the lower drive efficiency of the mains power and therefore the energy consumption (see Fig. 4 a). [5,6]/

1.Network operation mode; NM: 1

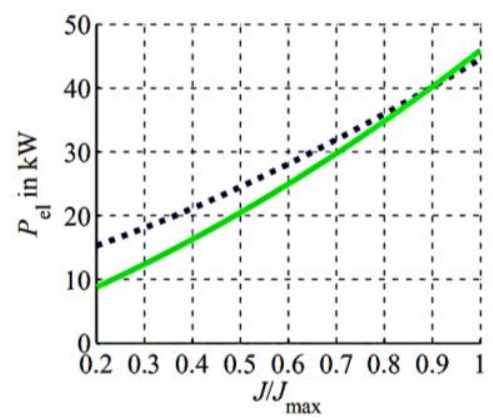

a) Estimated power consumption

Pel conveyor
2.Speed control; NM: 1

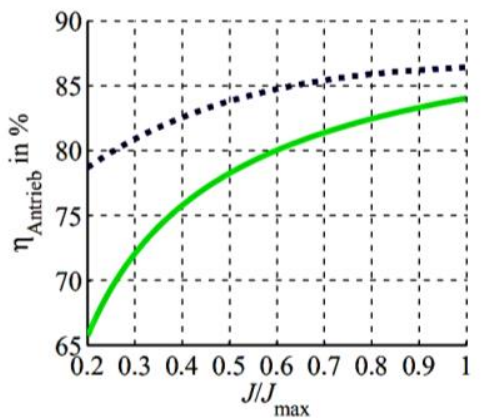

ь) rated electric efficiency of the electric drive $\eta \mathrm{dr}$

Fig. 4. Comparison of non-adjustable operation and speed control with one actuator NM = 1 drum

\section{Influence of ribbon width}

The belt width has a direct influence on the possible filling cross section. Reducing the cross-section of the belt requires an increase in belt speed and therefore an increase in energy consumption at the same output. As shown in the figure. 5, this results in an increase in belt width and a reduction in energy consumption. The energy saving potential in this example, if the belt width is doubled, is about $40 \%$. However, the investment cost of the belt also increases proportionally to the belt width, so that an optimal cost-optimal belt width must be estimated based on the depreciation calculation.

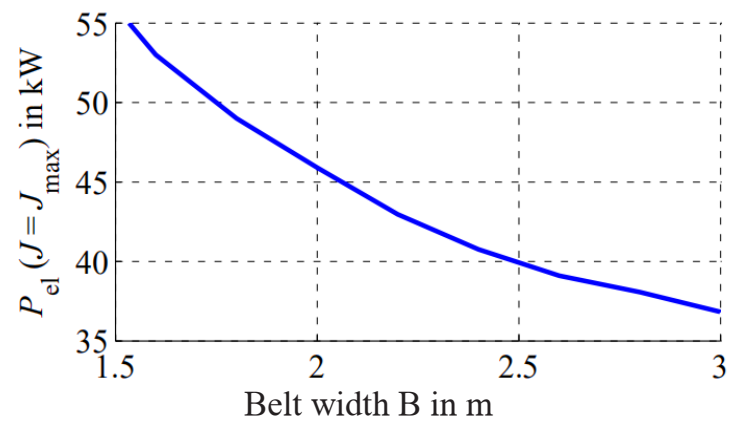

Fig. 5. Calculated energy consumption Pel with different belt widths

\section{Effect of Tension Force}

In the literature [7], the minimum possible belt tension force is selected as the belt tension force. In this case, the pulling force does not slide between the drum and the belt according to the Euler-Ethelwein formula. 


$$
\frac{T_{1}}{T_{2}} \leq e^{\mu T r \cdot \sigma}
$$

This minimum tension force is about $50 \mathrm{kN}$ in the investigated example and the corresponding distribution of forces is shown in the figure. 6 a. A tension force of $100 \mathrm{kN}$ results in a reduction of the sag and thus an increased bending resistance, as shown in figure $6 \mathrm{a} .6 \mathrm{~b}$. In the same way, the number of roller stations required, which reduces the rolling resistance. However, the tilt resistance is increased by increasing the weight per roller station and the bearing and belt wear is increased.

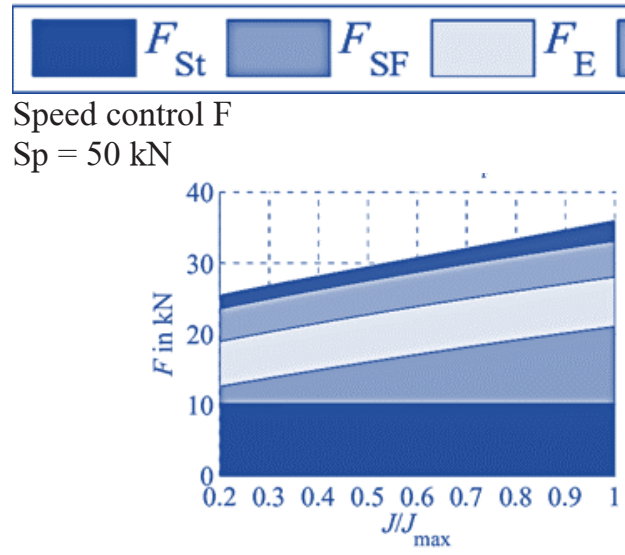

a) a conveyor with minimum clamping force FSp

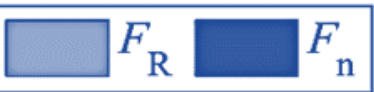

Speed control F

$\mathrm{Sp}=100 \mathrm{kN}$

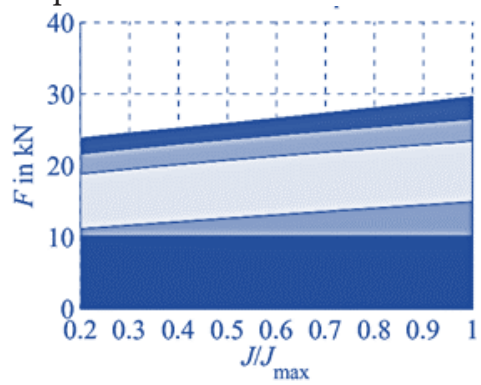

b) a conveyor with enlarged

clamping force FSp

Fig. 6. Calculated distribution of resistance $F$ for different tension forces

Fig. 7 compares the power consumption from the network with the minimum and increased belt tension. 7 a. The higher the tension force always results in lower power consumption. The calculation of the energy consumption for the different belt tension forces is shown in Fig. 7 б. In this example, the power consumption is about 3 to 4 times the tensile force (relative to the minimum tensile force). However, the choice of tension force must be based on the mechanical stress of the belt and its design. Too high a tension force therefore leads to belt heavier loads. Again, these heavy belts result in increased energy consumption with very high tension forces. Thus, there is an energetically optimized tension force, which for this calculation example has an energy saving potential of approx. $25 \%$.
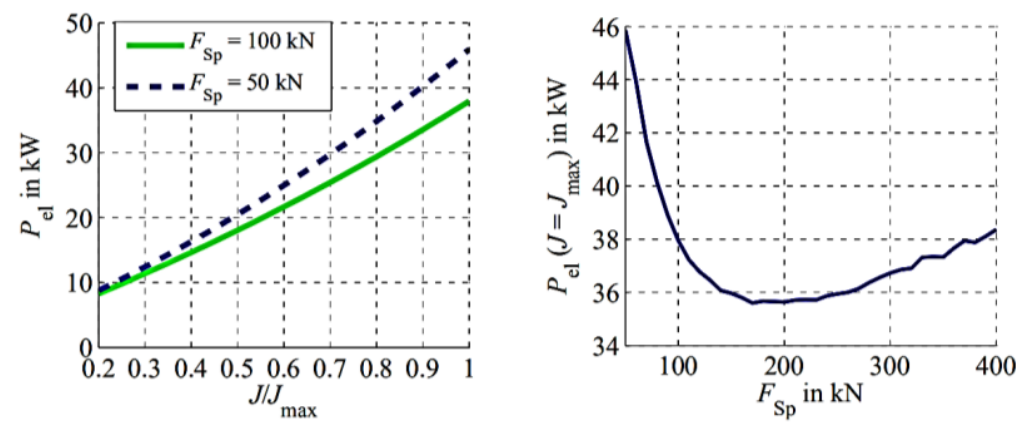

a) comparison of installations, b) power consumption 
shown in the figure. $6 \mathrm{a}, \quad$ depending on the tension force FSp and 6.b.

Fig. 7. Comparison of the calculated energy consumption of rahl for conveyor systems with different tension forces.

\section{Influence of tilt angle}

The multi-element conveyor system moves the material over several inclined sections with conveyor length $\mathrm{IF}$ and conveyor height $\mathrm{H}$, shown in Fig. 8. For two sections. the length of the conveyor belt lbant is determined by the sum of the following values: length L1 of the orizontal conveyor section and length L2 of the inclined conveyor section. The maximum angle $\delta$ max determines the position of the inclination point between the two sections.

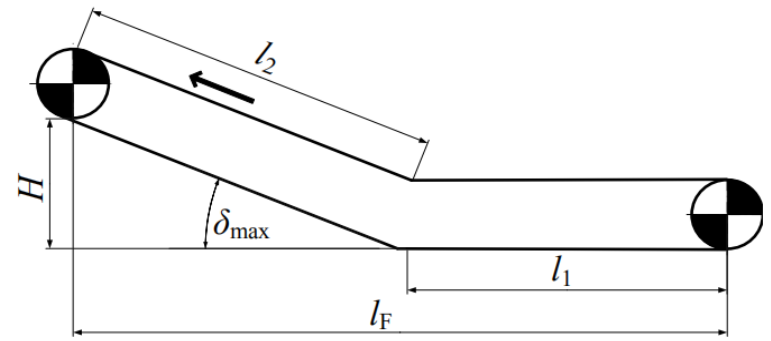

Fig. 8. Side view of the inclined belt conveyor with two inclined sections]

The dependence of the system power consumption on the maximum angle of slope is shown in Fig. 9. A large tilt angle (e.g. by increasing 11 and shortening 12) reduces the usable filling cross-section of the entire belt by "melting" the bulk material. This results in an increase in belt speed for the same load volume. The smallest possible slope angle results in minimum energy consumption [8]. Therefore, we recommend a linear connection with a low gradient, with an energy saving potential of approx. $10 \%$.

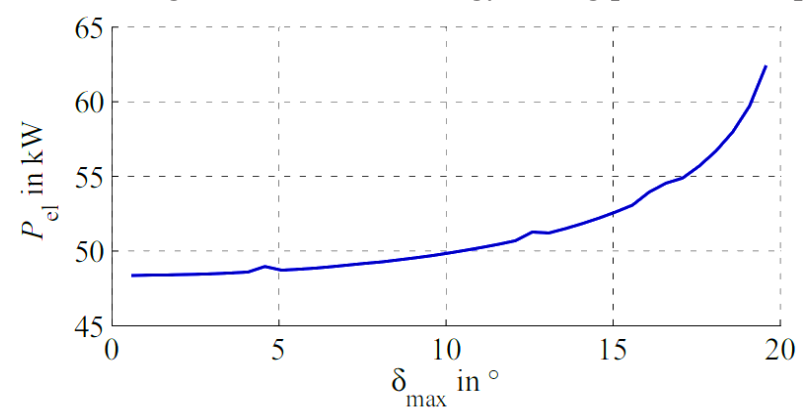

Fig. 9. Calculated energy consumption as a function of tilt angle

Influence of starting torque on engine selection

The starting torque of conveyor systems is estimated from the maximum starting force.

$$
F_{\mathrm{HH}}=1,5 F_{\mathrm{HaY}}
$$


According to (4), the required starting torque must be 1.5 times higher than the continuous torque for the rated operation of the conveyor system. Therefore, when designing the motor, the torque must be greater than the required torque during rated operation to avoid excessive motor size. However, most motors are designed for limited time overload, which can be used to obtain the required starting torque.

Most synchronous motors excited by permanent magnets can run for a short time with approximately 4 times the rated torque. In asynchronous motors with starting torque up to $\frac{m_{\text {anf }}}{m_{N}}=3 \ldots 4$

$m_{N} \quad$ In both variants, you must check whether the frequency inverter is running and can provide inrush current. For asynchronous motors operating in the fieldbus, the possible starting torque is lower, but most standard motors have a gear ratio of $\frac{m_{\text {anf }}}{m_{\mathrm{N}}}=2 \ldots 2,5$ displacement effect in the rotor winding. [9, 10].

Since a starting ratio of 1.3 to 1.6 is usually sufficient for conveyor systems, all the drive configurations mentioned above are suitable for starting a conveyor system. Separation of the motor design for increased starting torque is therefore not necessary (except for very frequent starting processes).

\section{Conclusions}

Thus, this selection system is used for conveyor belt systems and shows high energy saving potentials up to $40 \%$ for transport applications. For the analysis of energy-saving potentials in these complex conveying systems, all subsystems from the workflow to the conveying system and the drive are used. It is suitable for conveyor systems that eliminate safety factors for the load type and save both energy and investment costs.

\section{References}

1. K.S. Sanakulov, P.A. Shemetov, Mountain Newsletter of Uzbekistan, 2, 3-6 (2012)

2. Bundesministerium für Wirtschaft und Technologie (BMWi). Energie in Deutschland: Trends und Hintergründe zur Energieversorgung. 2013.

3. M.K. Bobojonov, Z.O. Eshmurodov, Problems of energy and resource saving, 1-2, 2427 (2016)

4. M.K. Bobozhonov, Z.O. Eshmurodov, Kh.T. Tasheva, Uzbek Journal of Problems of informatics and energy, 1, 84-89 (2018)

5. J. Schützhold, K. Benath, W. Hofmann, ant-Journal Heft, 3 (2014)

6. J. Schutzhold, K. Benat, W. Hoffmann. Calculation of speed and load dependencies of efficiency of electric machines is based on data in the data sheet. Special Report 139, (Int. ETG Congress, Berlin, 2013)

7. G. Kunze, H. Göhring, K. Jacob. Baumaschinen: Erdbau- und Tagebaumaschinen (Vieweg+Teubner, 2009)

8. M.K. Bobojonov, Z.O. Eshmurodov, M.T.Ismoilov, International Journal of Advanced Research in Science, Engineering and Technology, 6 (5), 9200-9207 (2019)

9. J. Schutzhold, W. Hoffmann, Selection criteria for energy-efficient electrical equipment Antriebstechnik (Congress SPS-IPC-Drives, Nuremberg, 2014) 